\title{
Ways to Use Allelopathic Potential for Weed Management: A Review
}

\author{
Tanveer Abbas ${ }^{1}$, Ali Ahmad ${ }^{1, *}$, Ahmad Kamal ${ }^{1}$, Muhammad Yasir Nawaz ${ }^{2}$, Muhammad Ahsan Jamil ${ }^{1}$, \\ Tasbiha Saeed ${ }^{1}$, Muhammad Asif Abid ${ }^{3}$, Hafiz Hussain Ali $^{4}$, Muhammad Ateeq ${ }^{5}$ \\ ${ }^{1}$ Department of Agronomy, University of Agriculture Faisalabad, Faisalabad, 38000, Pakistan. \\ ${ }^{2}$ Department of Pathology, Faculty of Veterinary Science, University of Agriculture Faisalabad, 38000, Pakistan. \\ ${ }^{3}$ Department of Horticulture, MNS-University of Agriculture, Multan, Punjab, Pakistan. \\ ${ }^{4}$ Institute of Soil and Environmental Sciences, University of Agriculture Faisalabad, Faisalabad, 38000, Pakistan. \\ ${ }^{5}$ College of Agriculture, BZU, Bahadur Sub Campus, Layyah 31200, Punjab, Pakistan.
}

How to cite this paper: Tanveer Abbas, Ali Ahmad, Ahmad Kamal, Muhammad Yasir Nawaz, Muhammad Ahsan Jamil, Tasbiha Saeed, Muhammad Asif Abid, Hafiz Hussain Ali, Muhammad Ateeq. (2021) Ways to Use Allelopathic Potential for Weed Management: A Review. International Journal of Food Science and Agriculture, 5(3), 492-498.

DOI: $10.26855 /$ ijfsa.2021.09.020

Received: July 8, 2021

Accepted: July 30, 2021

Published: August 31, 2021

*Corresponding author: Ali Ahmad, Department of Agronomy, University of Agriculture Faisalabad, Faisalabad, 38000, Pakistan.

Email: aliahmadsial2643@gmail.com

\begin{abstract}
A large number of plant and weed species produce secondary metabolites known as allelochemicals, and the process is known as allelopathy. Allelochemicals can be used to control weeds in agricultural systems by using allelopathic crops for intercropping, crop rotation, or mulching. A few important examples of crop species with high allelopathic potential may include (but not limited to) wheat, rice, sorghum, rye, barley, and sunflower. The naturally produced allelochemicals in these crops could be manipulated to suppress weeds and witness an environment-friendly and sustainable agricultural production system. The objective of this article is to review the opportunities for using allelopathy to enhance overall potentiality of weeds and crops in natural weed management. Allelopathy is the beneficial or adverse effect of one plant on another due to direct or indirect release of chemicals from live or dead plants (including microorganisms). Although we cannot discard use of synthetic herbicides completely at the present situation but their use can be reduced up to a specific extent by using allelopathic potentiality as a preferred weed management strategy for crop production as well as environmental benefits.
\end{abstract}

\section{Keywords}

Allelopathy, Herbicides, Herbicide Resistance, Weeds, Weed Management

\section{Introduction}

Weeds constantly compete with crop plants to cause a considerable loss in their productivity. Hence, weeds have been documented as serious plant pests since the ancient [1]. Weeds have always played a role throughout the domestication of crop plants which necessitated practicing weed control measures [2]. Pulling by hand, cutting, and physically smothering weeds were among the ancient methods of weed control [3]. Over time, hand tools were developed to till soils in order to control weeds. During recent times, herbicides and other modern means of weed control have been used. However, since the beginning of agriculture, hand weeding, mechanical weeding, and herbicide applications have been the most relied upon weed control methods [4-7]. These weed control methods have served to keep weed infestations low and improve the crop productivity throughout the world. Despite the significant contribution of these weed control methods in improving crop productivity, certain challenges are also associated with them. Decreasing availability and increasing cost of labour, and inconsistent weed control are among the major challenges in hand weeding [8, 9]. Similarly, mechanical weed control requires extra soil turn-over, which can disturb soil structure and deplete soil fertility [10]. Mechanical weed control is not always effective and can be expensive and lack durability [11]. Likewise, herbicide-resistant weeds, health effects, and environmental concerns are the major constraints for repeatedly using herbi- 
cides for weed control $[12,13]$.

The challenges associated with conventional weed control methods (e.g., hand weeding, mechanical control, herbicides, etc.) make it imperative to develop diversity in the current weed control methods. A variety of options would be available for site specific weed control if diverse weed management methods are developed. The cost and ecological concerns can be firmly addressed by using diversified weed management options. Suppressing weeds by harnessing the allelopathic phenomenon is included among the important innovative weed control methods [14]. Plant hormones and defence mechanisms are manipulated to control weeds in different agro-ecosystems [15]. This review article discusses the practical application of allelopathy for weed control in agricultural systems. Further, we have focused on the implications of weeds in crop production, challenges in weed management, potential allelopathic crops, and the use of allelopathy for managing weeds. Strategies, such as the use of allelopathic cultivars, intercropping with allelopathic weed suppressive plants, the use of allelopathic cover crops and residues, and rotational sowing of allelopathic crops, have been discussed for practical weed control in field crops.

\section{Allelopathy and weed management}

Weeds are the most stubborn competitors of crops causing substantial reduction in yield by sharing light, air, water, nutrients and space. Allelopathic water extracts have been successfully used for organic weed management. Allelochemicals are diverse in nature and structure and thus lack common mode of action. When applied at high concentrations, these allelochemicals interfere with the cell division, hormone biosynthesis and mineral uptake and transport [16], membrane permeability [17], stomatal oscillations, photosynthesis[18], respiration and protein metabolism and plant water relations [19], which may cause substantial growth reduction. This phytotoxic activity of allelochemicals is responsible for growth suppression of weeds. Flavonoids and phenolics suppressed the germination and growth of several plants [20]. Allelochemicals reduce water and nutrients uptake by roots and inhibit photosynthesis, respiration, protein synthesis, cell division and thickness of seminal roots as well as cause slow maturation and delay or failure of reproduction [21].

\section{Crops with allelopathic potential for weed control}

Several plants express the allelopathic phenomenon through exudation of allelochemicals. For example, rye is among the most important allelopathic crops. Although benzoxazinones [2,4-dihydroxy-1,4(2H)-benzoxazin-3-one (DIBOA) and 2(3H)-benzoxazolinone (BOA)] are the most important allelochemicals responsible for the allelopathic potential of rye, several of other important allelochemicals are also present in rye. Recently, Schulz, Marocco [22] reviewed the allelopathic potential of rye and listed 16 allelochemicals present in this plant. These allelochemicals included $\beta$-phenyllactic acid, protocatechuic acid, DIBOA (glucoside), vanillic acid, apigenin-glycosides, syringic acid, luteolinglucuronides, $p$-hydroxybenzoic acid, $p$-coumaric acid, benzoxazolinones BOA, cyanidin glycosides, $\beta$-hydroxybutric acid, isovitexinglucosides, DIMBOA (glucoside), gallic acid, and ferulic acid/conjugates. Further, a number of studies reported the allelopathic inhibition of other crops and weeds by rye [23-25]. Although rye can be manipulated to suppress weeds in a cropping system as a rotational crop, cover crop, or mulch, using it as a cover crop is the most common method for weed control.

Sorghum is another important allelopathic crop. Extensive literature explains the allelopathic potential of sorghum and its implications in different cropping systems. The allelopathic activity of sorghum varies across cultivars, environmental conditions, and plant growth stages. Sorghum expresses its allelopathic activity through the production of several allelochemicals. Most important among these allelochemicals are hydrophobic $p$-benzoquinone (sorgoleone), phenolics, and acyanogenic glycoside (dhurrin) [26]. Sorgoleone is the most potent allelochemical of sorghum exuded by its roots. Root hair cells are responsible for the production of sogoleone in sorghum plants [27]. The allelopathic activity of sorghum can be manipulated for weed control by planting allelopathic cultivars, applying sorghum residues as mulch, using sorghum as cover crop and intercrop, or including sorghum cultivars in a crop rotation.

The Brassicaceae family has a strong allelopathic potential against other crop and weed plants [28]. Brassicas produce the allelopathic compound glucosinolate throughout their plant parts [29]. However, the concentration of this allelochemical varies in different parts of the plant. Glucosinolate is released into the environment through either volatilization or decomposition. After the release, glucosinolate is decomposed into several biologically active compounds, such as isothiocyanate [30]. Further, these allelochemicals (isothiocyanates) suppress the growth and development of plants/weeds which take them up [31]. The allelopathic potential of brassica plants can be used to suppress weeds by using the brassica plants as cover crops, intercropping brassica crops with the main crop, crop rotation, or the use of brassica litter as mulch [32].

Sunflower is considered the most important allelopathic crop. Sunflowers can be phytotoxic to the following crop in a cropping rotation. Several weed species have also been reported to be suppressed by sunflower allelopathy. Recently, researchers evaluated the allelopathic potential of eight sunflower cultivars against problem weed species in wheat. 
They either grew the allelopathic sunflower cultivars in a mixture with weeds, or applied the residues (600 or 1,400 g $\mathrm{m}^{-2}$ ) of sunflower cultivars to the wheat crop and its weeds. The sunflower cultivars in the study varied in their allelopathic potential and suppressed total weed density by $10-87 \%$ and total weed biomass by $34-81 \%$. Sunflower residues also expressed their allelopathic potential to suppress total weed density (24-75\%) and total weed biomass (12-67\%), and increased wheat grain yield and yield components over the non-treated control. Further, 16 allelochemicals (phenolic acids) were found across the tested sunflower cultivars. The cultivars which suppressed weeds possessed higher concentrations of allelochemicals [33].

In conclusion, several crops have strong allelopathic potential, which is expressed through the exudation of a diversity of allelochemicals. The allelopathic potential of these crops can be manipulated to suppress weeds [34].

\section{Intercropping}

Growing of crops together (Figure 1) at the same time in the same field is an important strategy to increase input (land, fertilizer, and water) use efficiency and to enhance crop yield and economic returns [35]. In addition, intercropping especially with allelopathic crops can provide eco-friendly alternative to chemical weed control [36]. Recent studies have explored the effectiveness of intercropping with allelopathic crops as a good alternative to chemical weed control [37]. Intercropping of fodder legumes in maize helped to control the giant witchweed (Striga hermonthica [Del.] invasion than the sole maize crop [38]. Intercropping of various allelopathic crop species in maize was effective to control different narrow and broad leaved weed species [39]. Infestation of purple nutsedge (Cyperus rotundus L.) in cotton crop was significantly reduced with intercropping of sesame (Sesamum indicum L.), soybean, and sorghumon alternate rows [40]. In another field trail, the intercropping of white clover (Trifolium repens L.), black medic (Medicago lupuli$n a \mathrm{~L}$.), alfalfa, and red clover (Trifolium pratense L.) in wheat crop was effective to control various weed species and to enhance wheat yield [41]. Similarly, intercropping of pea (Pisum sativum L.) with barley (Hordeum vulgare L.) [42], sorghum with cowpea (Vigna unguiculata (L.) Walp.) [43], wheat with canola [44], and wheat with chickpea (Cicer arietinum L.) [45], reduced the weed infestation as compared to sole crop and enhanced farm income. Therefore, intercropping of allelopathic crops with the main crop has potential to control weeds through release of allelochemicals.

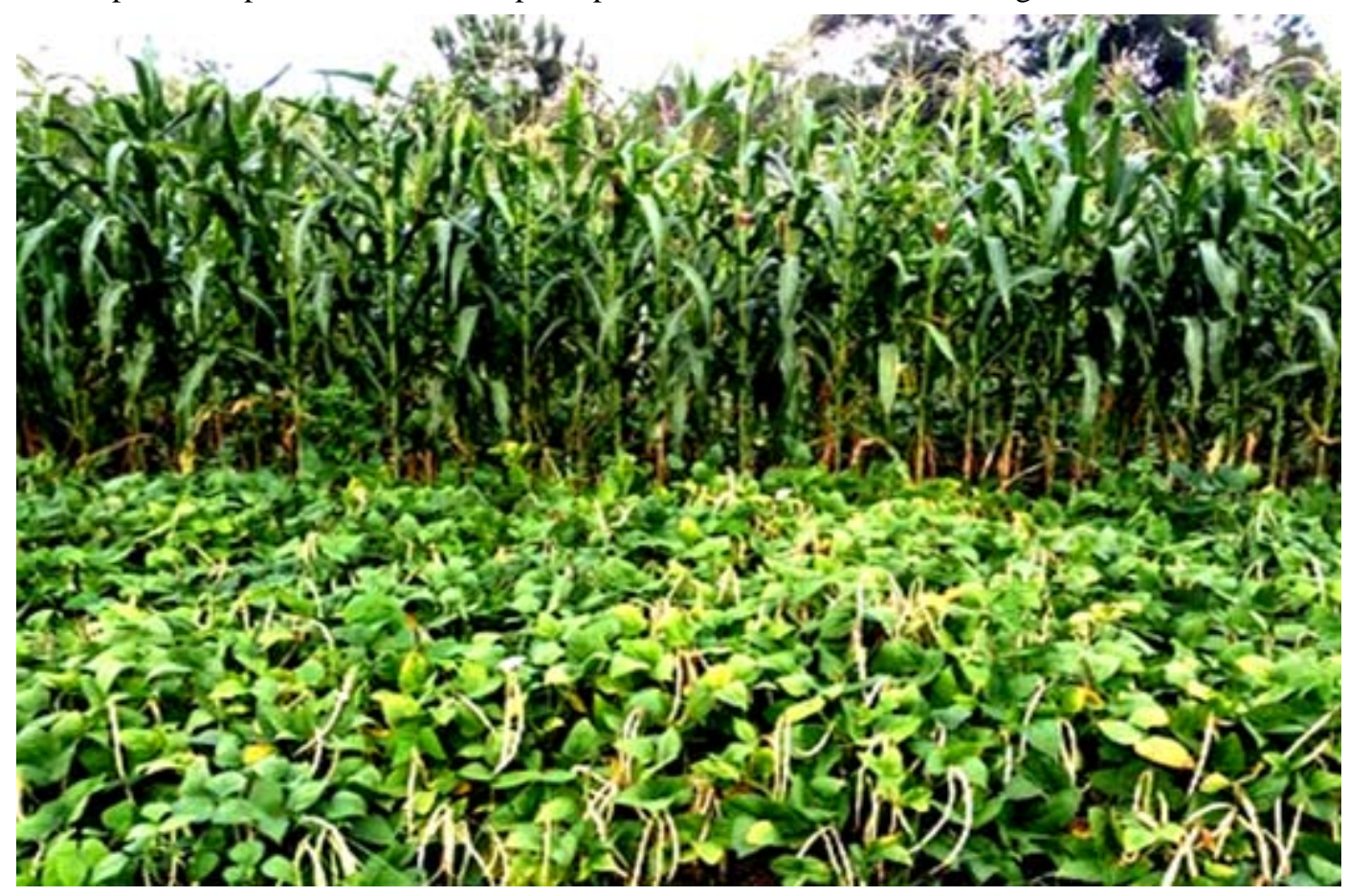

Figure 1. Intercropping of mung bean and maize.

\section{Cover Crops}

Cover crops with allelopathic properties can provide effective weed control in addition to their other benefits including protection from soil erosion, snow trapping, nitrogen fixations, and improvement of soil structure and fertility [46]. The weed suppression potentials of cover crops including physical suppression, shade effect, decrease in temperature, and competition with weeds for inputs can be further increased through selection of strong allelopathic crops as cover crops. Furthermore, the release of allelochemicals from cover crops through root exudates, leaf shading, and washing by 
rain will help to decay the weed seed bank. The weed control efficiency of cover crops depends on its allelopathic potential and duration in the field; strong allelopathic crop for long duration in the field will provide more efficient weed control [47]. The weed control efficiency of cover crops also depends on weed species, e.g., sorghum as cover crop provides effective control of broad-leaved weeds; however narrow-leaved weeds were not controlled [48]. Environmental factors also influence weed control potential of cover crops by changing allelopathic potential, e.g., rye grown under nutrient stress conditions was more phytotoxic as compared to rye grown under high fertility [49]. Herbicide-resistant weeds, which are a major problem for sustainable weed management, maybe controlled with allelopathic cover crops. The allelopathic crops that can be used as cover crops include rye, barley, sorghum, oat, wheat, canola, black mustard, buckwheat, clover species, and hairy vetch [50,51]. In a recent study, allelopathic cover crops such as buckwheat and hairy vetch were effective in controlling apricot weeds [52].

\section{Crop Rotation}

Crop rotation is system in which different plants are grown in a sequence in a specific field for definite time period. It is important to reduce pest (weeds, pathogens, and insects) pressure, to overcome autotoxicity, and to sustain soil fertility [53]. Diversified rotation is key for sustainable weed control as it creates unstable conditions for weeds and helps to reduce weed seedbank [54]. Allelopathic crop in a rotation can potentially suppress its associated weeds and reduce weed infestation in the crop following in the rotation [55]. Both root exudates and decomposing crop residues an allelopathic crop in the rotation add allelochemicals to the soil that help to reduce weed pressure [56]. For example, weed infestation is reduced in wheat crop if grown following the sorghum crop due to release of allelochemicals from sorghum [57]. For instance, in sunflower-wheat rotation, the weed infestation in wheat crop grown after sunflower was considerably reduced [58]. Inclusion of rapeseed in rotation caused about $40 \%$ reduction in weed density in the subsequent crop in rotation [59]. Weed seed germination inhibition potential of allelopathic crop in rotation can also negatively affect the seed germination of subsequent crop in rotation. For example, wheat germination was delayed when it was grown in rotation with sorghum [60]. However, wise use of allelopathic crops in rotation and tillage timing can help to reduce the inhibitory effect on crop [61]. Therefore, good crop rotation with inclusion of allelopathic crop can help to avoid autotoxicity and to reduce weed problem with minimum dependence on chemical weed control method.

\section{Mulching and Residue Incorporation}

In allelopathic mulching (Figure 2), the crop or weed residues are applied on soil surface or incorporated in the soil. Mulching with allelopathic crop/weed residues inhibits weed germination and growth due to release of allelochemicals in the rhizosphere, physical suppressing and depriving weed seeds from light [62]. In addition to weed control, mulching increases water holding capacity, increases soil fertility, enhances organic matter, and works as buffer to maintain soil temperature [62]. Commonly, farmers use economic parts of the crop while incorporating the remaining crop parts in the field as organic matter. The allelopathic plant parts left in the field inhibit the weeds. Recently, many studies have been done to explore the weed control potential of allelopathic mulches and residue incorporation in fieldcrops. For instance, application of sorghum crop straw as surface mulch in maize provided up to 37\% weed control [63], while in cotton and rice, about $60 \%$ and 50\% weed control, respectively, was achieved with sorghum surface mulch [64, 65]. Sorghum residue incorporation or surface mulches provided effective control of various noxious weed species including C. rotundus, broad leaved dock (Rumex obtusifolius L.), P. minor, C. arvensis, C. album, and scarlet pimpernel (Anagallis arvensis L.) [66]. In another field study, it was observed that maize residues added in the field after maize harvest caused significant reduction in weed infestation in the succeeding $510 \mathrm{~N}$. Broccoli (Brassica oleracea L.) crop [67]. Similarly, sunflower residues and surface mulches have potential to control various weed species in the field crops. In another study, application of barely mulch in maize provided up to $80 \%$ weed control and $45 \%$ increase in maize grain yield over control [68]. The mulches of allelopathic crops including rice, maize, sorghum, and sunflower at $12 \mathrm{t} \mathrm{ha}^{-1}$ provided effective control of herbicide-resistant P. minor in wheat. Mulches and residues of various crops including rye, clover, rice, maize, and canola have been reported for their potential as weed control [69].

Combined use of different allelopathic mulches can enhance their weed control potential due to the availability of diverse allelochemicals. Furthermore, allelochemicals have been known for their synergistic effect [70]. For example, combined use of canola, sunflower, and sorghum mulches provided more efficient weed control in maize as compared to the sole use of individual mulch material. Therefore, residues of allelopathic crops can be used either as surface mulch or soil residue incorporation to control weeds in different crops [71].

\section{Conclusion}

So it is clear from the above discussion that there is massive prospect of allelopathic mechanism as a weed management tool. Allelochemicals from several plants have been identified and their activities have also been well-known. Allelopathic weed control can provide environmentally friendly tool to control weeds in cropping systems without depen- 
dence on chemical herbicides, as chemical weed control causes various hazards to environment, biodiversity, and human health. The use of allelopathic weed control through intercropping, crop rotation, cover cropping, mulches, residues, and water extract alone or in combination with synthetic herbicides will not only provide sustainable weed control but also sustainable crop production due to positive effects of these strategies on soil fertility, organic matter contents, and ecosystem biodiversity. Furthermore, efforts to motivate industries to produce allelochemical-based herbicides, breeding of more weed suppressive crop cultivars, exploring the allelopathy of unexplored fields, the use of allelochemical hormesis, and understanding about mode of action of allelochemicals will enhance the efficacy of allelopathic weed control.

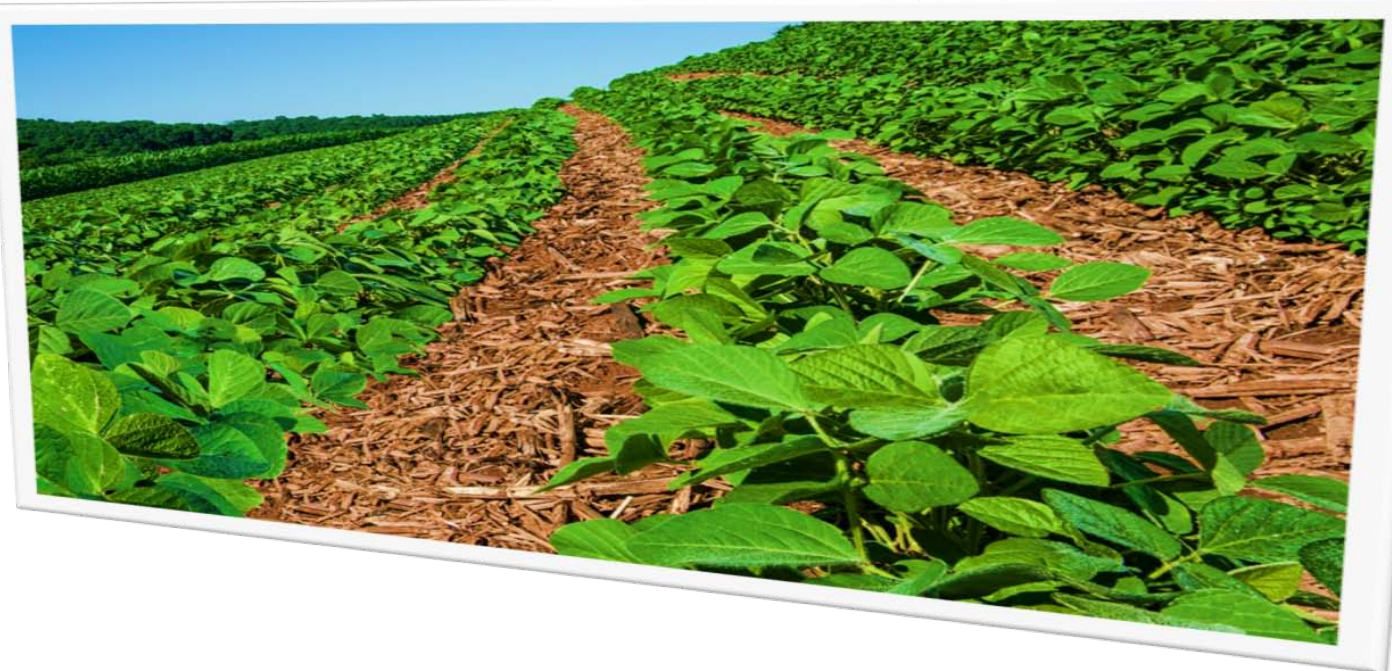

Figure 2. Mung bean mulch with sunflower residues.

\section{References}

[1] Zimdahl, R. L. (2018). Fundamentals of weed science. Academic press.

[2] Oerke, E.-C. and H.-W. J. C. P. Dehne. (2004). Safeguarding production-losses in major crops and the role of crop protection. 2004, 23(4): pp. 275-285.

[3] Young, S. L., F. J. Pierce, and P. Nowak. (2014). Introduction: Scope of the problem-rising costs and demand for environmental safety for weed control, in Automation: The future of weed control in cropping systems. 2014, Springer. Pp. 1-8.

[4] Griepentrog, H. W. and A. P. Dedousis. (2010). Mechanical weed control, in Soil Engineering. 2010, Springer. Pp. 171-179.

[5] Bergin, D. J. N. Z. F. R. I. L. (2011). Weed control options for coastal sand dunes: a review. 2011: pp. 5-13.

[6] Rueda-Ayala, V., et al. (2011). The influence of post-emergence weed harrowing on selectivity, crop recovery and crop yield in different growth stages of winter wheat. 2011. 51(5): pp. 478-488.

[7] Chauvel, B., et al. (2012). History of chemical weeding from 1944 to 2011 in France: Changes and evolution of herbicide molecules. 2012. 42: pp. 320-326.

[8] Carvalledo, J., et al. (2013). Field sprayer for inter- and intra-row weed control: performance and labor savings.

[9] Gianessi, L. P. J. P. m. s. (2013). The increasing importance of herbicides in worldwide crop production. 2013. 69(10): pp. 1099-1105.

[10] Smith, R. G., et al. (2011). Direct and indirect impacts of weed management practices on soil quality. 2011 (soil management b): pp. 275-286.

[11] Bond, W. and A. J. W. r. Grundy. (2001). Non-chemical weed management in organic farming systems. 2001. 41(5): pp. 383-405.

[12] Annett, R., H. R. Habibi, and A. J. J. o. A. T. Hontela. (2014). Impact of glyphosate and glyphosate-based herbicides on the freshwater environment. 2014. 34(5): pp. 458-479.

[13] Hoppin, J. A. (2014). Pesticides and respiratory health: where do we go from here? 2014, BMJ Publishing Group Ltd.

[14] Jabran, K. and M. Farooq. (2013). Implications of potential allelopathic crops in agricultural systems, in Allelopathy. 2013, Springer. Pp. 349-385.

[15] Pickett, J. A., et al. (2014). Delivering sustainable crop protection systems via the seed: exploiting natural constitutive and inducible defence pathways. 2014. 369(1639): pp. 20120281. 
[16] Rizvi, S., et al. (1992). A discipline called allelopathy, in Allelopathy. 1992, Springer. Pp. 1-10.

[17] Harper, J. R. and N. E. J. P. P. Balke. (1981). Characterization of the inhibition of K+ absorption in oat roots by salicylic acid. 1981. 68(6): pp. 1349-1353.

[18] Einhellig, F. A. and J. A. J. J. o. C. E. Rasmussen. (1979). Effects of three phenolic acids on chlorophyll content and growth of soybean and grain sorghum seedlings. 1979. 5(5): pp. 815-824.

[19] Rice, E. L. (2012). Allelopathy. 2012.

[20] Sadeghi, S., et al. (2010). Allelopathie effect of Helianthus annuus on Solanum nigrum seed germination and growth in laboratory condition. 2010. 2(1): pp. 32-37.

[21] Jafariehyazdi, E., F. J. P. Javidfar. (2011). Soil, and Environment, Comparison of allelopathic effects of some brassica species in two growth stages on germination and growth of sunflower. 2011. 57(2): pp. 52-56.

[22] Schulz, M., et al. (2013). Benzoxazinoids in rye allelopathy-from discovery to application in sustainable weed control and organic farming. 2013. 39(2): pp. 154-174.

[23] Bertholdsson, N. O., S. C. Andersson, and A. J. P. B. Merker. (2012). Allelopathic potential of Triticum spp., Secale spp. and Triticosecale spp. and use of chromosome substitutions and translocations to improve weed suppression ability in winter wheat. 2012. 131(1): pp. 75-80.

[24] Didon, U. M., et al. (2014). Cover crop residues-effects on germination and early growth of annual weeds. 2014. 62(2): pp. 294-302.

[25] Macías, F. A., et al. (2014). Evidence for an allelopathic interaction between rye and wild oats. 2014. 62(39): pp. $9450-9457$.

[26] Weston, L. A., I. S. Alsaadawi, and S. R. J. J. o. C. E. Baerson. (2013). Sorghum allelopathy-from ecosystem to molecule. 2013. 39(2): pp. 142-153.

[27] Weston, L. A., P. R. Ryan, and M. J. J. o. e. b. Watt. (2012). Mechanisms for cellular transport and release of allelochemicals from plant roots into the rhizosphere. 2012. 63(9): pp. 3445-3454.

[28] Haramoto, E. R., E. R. J. R. a. Gallandt, and f. systems. (2004). Brassica cover cropping for weed management: a review. 2004. 19(4): pp. 187-198.

[29] Fahey, J. W., A. T. Zalcmann, and P. J. P. Talalay. (2001). The chemical diversity and distribution of glucosinolates and isothiocyanates among plants. 2001. 56(1): pp. 5-51.

[30] Weston, L. A. and S. O. J. C. r. i. p. s. Duke. (2003). Weed and crop allelopathy. 2003. 22(3-4): pp. 367-389.

[31] Bangarwa, S. K. and J. K. J. J. o. C. I. Norsworthy. (2014). Brassicaceae cover-crop effects on weed management in plasticulture tomato. 2014. 28(2): pp. 145-158.

[32] Narwal, S. and R. Haouala. (2013). Role of allelopathy in weed management for sustainable agriculture, in Allelopathy. 2013, Springer. Pp. 217-249.

[33] Alsaadawi, I. S., et al. (2013). Differential allelopathic potential of sunflower (Helianthus annuus L.) genotypes on weeds and wheat (Triticum aestivum L.) crop. 2012. 58(10): pp. 1139-1148.

[34] Jabran, K., et al. (2015). Allelopathy for weed control in agricultural systems. 2015. 72: pp. 57-65.

[35] Khan, M. B., et al. (2012). Bio-economic assessment of different wheat-canola intercropping systems. 2012. 14(5).

[36] Jabran, K. and B. Chauhan. (2018). Non-chemical weed control. 2018: Academic Press.

[37] Farooq, M., et al. (2011). The role of allelopathy in agricultural pest management. 2011. 67(5): pp. 493-506.

[38] Khan, Z. R., et al. (2002). Control of witchweed Striga hermonthica by intercropping with Desmodium spp., and the mechanism defined as allelopathic. 2002. 28(9): pp. 1871-1885.

[39] Nawaz, A., et al. (2014). Role of allelopathy in weed management, in Recent advances in weed management. 2014, Springer. Pp. 39-61.

[40] Abraham, C. and S. J. T. J. o. A. S. Singh. (1984). Weed management in sorghum-legume intercropping systems. 1984. 103(1): Pp. 103-115.

[41] Naeem, M. (2011). Studying weed dynamics in wheat (Triticum aestivum L.)-canola (Brassica napus L.) intercropping system. 2011, M. Sc. thesis, Department of Agronomy, University of Agriculture, Faisalabad.

[42] Banik, P., et al. (2006). Wheat and chickpea intercropping systems in an additive series experiment: advantages and weed smothering. 2006. 24(4): pp. 325-332.

[43] Tursun, N., et al. (2018). Use of living, mowed, and soil-incorporated cover crops for weed control in apricot orchards. 2018. 8(8): p. 150.

[44] Bhowmik, P. C. J. C. p. (2003). Challenges and opportunities in implementing allelopathy for natural weed management. 2003. 22(4): pp. 661-671.

[45] Einhellig, F. A. and G. R. J. J. o. C. E. Leather. (1988). Potentials for exploiting allelopathy to enhance crop production. 1988. 14(10): pp. 1829-1844. 
[46] Mwaja, V. N., J. B. Masiunas, and L. A. J. J. o. c. e. Weston. (1995). Effects of fertility on biomass, phytotoxicity, and allelochemical content of cereal rye. 1995. 21(1): pp. 81-96.

[47] Cheema, Z. A., M. Farooq, and A. Khaliq. (2013). Application of allelopathy in crop production: success story from Pakistan, in Allelopathy. 2013, Springer. Pp. 113-143.

[48] Teasdale, J. R., et al. (2004). Weed seed bank dynamics in three organic farming crop rotations. 2004. 96(5): pp. $1429-1435$.

[49] Liebman, M. and E. J. E. a. Dyck. (1993). Crop rotation and intercropping strategies for weed management. 1993. 3(1): pp. 92-122.

[50] Mamolos, A. and K. J. J. o. c. p. Kalburtji. (2001). Significance of allelopathy in crop rotation. 2001. 4(2): pp. $197-218$.

[51] Einhellig, F. A. and J. A. J. J. o. C. E. Rasmussen. (1989). Prior cropping with grain sorghum inhibits weeds. 1989. 15(3): pp. 951-960.

[52] Roth, C. M., J. P. Shroyer, and G. M. J. A. J. Paulsen. (2000). Allelopathy of sorghum on wheat under several tillage systems. 2000. 92(5): pp. 855-860.

[53] Conklin, A. E., et al. (2002). Effects of red clover (Trifolium pratense) green manure and compost soil amendments on wild mustard (Brassica kaber) growth and incidence of disease. 2002. 238(2): pp. 245-256.

[54] Abbas, T., et al. (2016). Mulching with allelopathic crops to manage herbicide resistant little seed canarygrass. 2016. 16(1).

[55] Bilalis, D., et al. (2003). Effect of different levels of wheat straw soil surface coverage on weed flora in Vicia faba crops. 2003. 189(4): pp. 233-241.

[56] Jabran, K. and B. S. Chauhan. (2018). Overview and significance of non-chemical weed control, in Non-Chemical Weed Control. 2018, Elsevier. Pp. 1-8.

[57] Jabran, K. and B. S. Chauhan. (2018). Weed control using ground cover systems, in Non-Chemical Weed Control. 2018, Elsevier. Pp. 61-71.

[58] Jabran, K., et al. (2015). Mulching improves crop growth, grain length, head rice and milling recovery of basmati rice grown in water-saving production systems. 2015. 17(5).

[59] Jabran, K., et al. (2015). Mulching improves water productivity, yield and quality of fine rice under water-saving rice production systems. 2015. 201(5): pp. 389-400.

[60] Younis, A., et al. (2012). Effect of different types of mulching on growth and flowering of Freesia alba cv.'Aurora'. 2012. 49(4): pp. 429-433.

[61] Cheema, Z., A. Khaliq, and S. J. J. o. S. A. Saeed. (2004). Weed control in maize (Zea mays L.) through sorghum allelopathy. 2004. 23(4): pp. 73-86.

[62] Riaz, M. J. M. T. (2010). Department of Agronomy, University of Agriculture, Faisalabad, Pakistan, Non-chemical weed management strategies in dry direct seeded fine grain aerobic rice (Oryza sativa L.). 2010.

[63] Mahmood, A. and Z. J. I. J. A. B. Cheema. (2004). Influence of sorghum mulch on purple nutsedge (Cyperus rotundus L.). 2004. 6(1): pp. 86-88.

[64] Bajgai, Y., et al. (2015). Comparison of organic and conventional managements on yields, nutrients and weeds in a corn-cabbage rotation. 2015. 30(2): pp. 132-142.

[65] Rawat, L. S., et al. (2017). Sunflower allelopathy for weed control in agriculture systems. 2017. 20(1): pp. 45-60.

[66] Dhima, K., et al. (2006). Allelopathic potential of winter cereals and their cover crop mulch effect on grass weed suppression and corn development. 2006. 46(1): pp. 345-352.

[67] Khaliq, A., et al. (2011). Effect of crop residues applied isolated or in combination on the germination and seedling growth of horse purslane (Trianthema portulacastrum). 2011. 29: pp. 121-128.

[68] Jabran, K. (2017). Manipulation of allelopathic crops for weed control. 2017: Springer.

[69] Jamil, M. A., et al. (2021). Role of Allelopathy for Suppression of Parthenium hysterophorus: A Review. 2021.

[70] Tabaglio, V., A. Marocco, and M. J. I. J. o. A. Schulz. (2013). Allelopathic cover crop of rye for integrated weed control in sustainable agroecosystems. 2013. 8(1): pp. e5-e5.

[71] Ali, M. F., et al. (2021). Bio-Medical Importance of Agronomic Weeds: An Overview. 2021. 8(1): pp. 1-8. 